\title{
Alcohol and Drug Dependence among Rural Youth in Bathinda District of Punjab
}

\author{
Author \\ Kamaljit Kaur Dhillon
}

Research Scholar Desh Bhagat University Mandi, Gobindgarh (Punjab) India

\begin{abstract}
Punjab is in the grip of drug epidemic of gargantuan dimensions. Drug addiction has become a most endemic to Punjab. The worst affected areas are village's jassipauwali and katarsingh of district Bathinda in Punjab. About, 5000 people in this village, 1000 are alcohol and other drug addicts. The most vulnerable population age is 15-35 yrs. This is the real thing school boys hooked on synthetic drugs. Young men who shoot up in hovels, streets littered with empty syringes, .The rich prefer heroine, while the poor make do with synthetic drugs. The study on youth was conducted using interview schedule method to collect data from respondents so that answer to the objectives can be found. The study results make some interesting revelations.

Key words:- Drug addiction, vulnerable population, epidemic, remedies.
\end{abstract}

\section{Introduction}

The use of drug is not a recent phenomenon, since it was very popular for a varied of reasons in different societies. However, Drug - addiction is a world - wide problem nowadays. India too has fallen a prey to this menace. Earlier there were few restrictions on drug availability during the beginning of $20^{\text {th }}$ century and very few efforts were made to decrease or eliminate certain substances. Hence use of drugs tend to flourish effectively moreover, careless attitude of authorities made the drug trade open and flours Indian youth is literally drowned in drugs today. But in recent times drug craving as a social problem has assumed serious proportions in India, as well as its adverse physical and psychological effects are extremely unknown to the society as a whole.
Man has been using drugs and other narcotics from time immemorial. But, it is assuming alarming proportions of late, especially in Bathinda district of Punjab. Drug abuse harms everybody and does good to none. Government, society, family, the individual drug user and the public-all suffer because it is a social problem. it has been suggested that there may be a link between the marked declines in scholastic achievement of the youth of today and increase in illegal drug use among them. The drug abuse has been realized as a complex phenomenon, which has various social, cultural, biological, geographical, and historical and economic aspects to it. The plausible reasons for the drug use amongst youngsters are: disintegration of the joint family system, absence of parental love and care in modern families where both parents are 
working, decline of old religious and moral values etc, which lead to a rise in the number of drug addicts who take drugs to the escape hard realities of life. The processes of industrialization, urbanization and migration have also lead to loosening of the traditional methods of social control, rendering an along with sound education system, provision of vocational opportunities and by Establishment individual vulnerable to the stresses and strains of modern life. The introduction of synthetic drugs and intravenous drug use leading to HIV/AIDS, has added a new dimension to the problem. Thus the drug abuse has a strong detrimental impact on the society, which leads to the increase in the crime rate. This complex problem can, however, be resoveled with the concerted efforts of law enforcing agencies of many more rehabilitation centre's for the drug Addicts. It is agonizing that the drug trafficking is the third largest business in the world after petroleum and arms trade as a result of which millions of drug addicts all over the world, are leading miserable lives, hanging between life and death the world community has taken an initiative against it to sensitize the people in people in the youth in particular to the menace of drugs. June 26 is now celebrated as international day against drug abuse and illicit trafficking every year. It has been identified that the chemists along with quacks, drug peddlers and truck drivers are main supply sources of drugs in rural areas of Malwa region of Punjab. Chemists provide drugs to the addicts without any prescription. Even many of the so called de- addiction centres are actually proving to be addiction centres and are supplying drugs to the inmates. The numbers of chemist shops and deaddiction centres have increased in the malwa region in the recent years it has also been observed that the private de- addiction centres lack basic facilities though they earn a quick buck. In Punjab, drug addiction is a cancer which is crippling the mental the and physical well being of the youth population of Punjab. A report by the WHO stated that drug use in a growing problem in both the developed and developing world. Along with the United States, Japan and Sweden have "large scale epidemics of amphetamine abuse. The impact of drug abuse among Punjabi youths has been a hallmark of a morally bankrupt decadent and wasted generation and loss of our societal values and ideas. The use of drugs is not a recent phenomenon, since it was very popular for a varied of reasons in different societies. However, Drug- addiction is a world- wide problem nowadays. India too has fallen a prey to this menace. Earlier there were few restrictions on drug availability, but during the beginning of $20^{\text {th }}$ century and very few efforts were made to eliminate certain substances. Hence uses of drugs tend to flourish effectively. Moreover, careless attitude of authorities made the drug trade open to the Indian youth. But in recent times drug addiction a social problem has assumed serious proportions in India. A large number of youths who are some reason or other are finding. Solace in drugs to their everyday stresses and strains. Hence alienated youths remain confined within their own "youth culture "who get engrossed in "drug culture". An alarming fact is that the majority of illegal drug users happen to belong to the "outcaste" groups like criminals and prostitutes etc. With the result that is loss of productivity, increase in crime and violence, loss of life in street accidents, deterioration of intelligence, spread of HIV/AIDS and other sex related diseases, and different forms of deviance. In almost all the Metropolitan cities in India drugabuse has assumed a serious threat. Besides, due to globalization many developing countries have facing problem of drug abuse these days.

\section{Literature review}

A number of research studies have been undertaken through- out the world to examine various problems related with drug addiction and drug abuse. In the European countries the studies have brought within their purview different dimensions of the problem. In Asia, scholars have discussed various aspects of the problem and thereby have attempted to throw light on very 
important issues and tried to bring awareness among the masses regarding effects of drug addiction. However, due to certain limitations, it is not possible for the researcher to discuss all the studies on the subject, so some of the studies have been briefly discussed.

M.C.Paul (1996) tried to study the drug addiction prevailing among youth belonging to now era rich class so called high society in urban areas not only male but females as well in metropolitan cities and its effects on the youth on particular. The study also revealed the role of authorities and other agencies. i.e., then wide network of operations with regard to elicit manufacturing \&role of cultivators.

Uddin (1997) in his study tried to study the magnitude of the problem related to drugs its effects as well as tried to analyze the psychological and sociological aspect critically. $\mathrm{He}$ also highlighted the various issues such as cultivation, production, smuggling and trafficking etc and the present study focused mainly on legal aspect and numerous suggestions to combat this problem.

Virk (2002) in his study, he tried to depict different aspects of drug addiction among youths at school, college and university level. This study suggests various ways to help out the drugabusers and to prevent the epidemic of this menace among vulnerable segments of the society.

Sudhir Kumar (2004) studied drug addiction among the youth in Calcutta. The study highlights the nature and extent of drug use among lower and middle class youths. He tried to analyze the influence of different social, economic and psychological factors on drug - dependence. The study reveals that in order to have in- depth knowledge and understanding of drug- addiction, greater emphasis should be paid upon sociocultural factors.

Sharma (2005) studied substance abuse in contemporary India into account two states i.e., Punjab and Rajasthan. It's a comparative study highlights socio- cultural and economic factors related to health services. The study also reveal various aspects such caste, creed, religion, customs that play a vital role in consuming drugs. Gulalia, Akash (2010) tried to study Alcohol and Drug abuse prevention and rehabilitation performance in India. The study mainly focuses on to create awareness and educating the people about the ill- effects of substance abuse on the individual, family and society. The study provides an insight on the various issues such as prevention and rehabilitation of drug- addicts.

\section{Objectives}

- To study the prevalence of drug abuse among the youth in Bathinda district of Punjab.

- To determine nature \& extent of drug use and identify the sources of supplying of drugs.

- To examine the causes and general effect of drug abuse in the area of its operation.

\section{Cause of drug abuse}

Unemployment, peer pressure, culture of consumption, masculinity, mix of frustration, boredom, laziness, thrill seeking, curiosity, lack of support during stress, low self- worth.

\section{The effects of drugs}

Drugs alter the mood, function, understanding and awareness of the drug user by acting on the central nervous system and other parts of the body. The effects of any drugs are hard to predict since they dependent on the amount of drug taken, the way it is taken, the personality of the user and the setting in which it is taken.

\section{Sample}

In the present study due to the vastness of the universe ," snowball" sampling technique will be applied to locate the drug abusers through their fellow addicts ; the peer group ; ex-addicts could also be helpful in providing useful insight into phenomena of drugs. Its assumed that research on drug abuse may pose several problems for the 
researcher. Since it is very difficult to identify the hidden population i.e. those segments of society which are often omitted from national survey because they have no fixed address. Moreover, drug addicts are elusive human category. The study will be done secretive manner, since they are neither easily visible nor easily available the basic problem will be to locate the sources as well as the areas. This technique was used because it was obvious, that sampling frame does not exist and the best method of selection was through personal contacts. The problem arises out of the very sensitive character of the behaviour of drug abuse. This collection of information through door to door survey is practically impossible. It is equally dangerous for a single interviewer to collect information from the drug den. In view of this few NGO'S from Bathinda have been selected from where the sample population has to be drawn. Drug addicted persons to attend the civil hospital OPD and admitted in civil hospital Bathinda for detoxification .The researcher interviewed 500 willing respondents from rural and urban persons from Bathinda district .

\section{Method of data collection}

1. In the present study, the interview schedule method was used which consisted of 60 questions. The method was considered the most suitable method of data collection for present study due to the following reasons. In order to create and establish rapport with respondents which was very essential to collect data on such a personal type of study.

2. Moreover the researcher wanted to have a direct and personal contact with the respondents in order to get information on tact's like family background of drug addicts, personal socio- economic and demographic profile of drug users causes of drug addiction, age at first experience, types of drugs, nature of marital life etc.
3. By this method it was easier to explain the meanings and its misunderstanding which might develop.

\section{Interview Process}

Before starting the actual data collection, the researcher had visited many times the respondents through working in the field, the social worker to establish good rapport with the respondents. This introductory meeting had facilitated the researcher to build up good rapport with the respondent.

\section{SUMMARY}

This study is exploratory study about the "DRUG ABUSE AMONG THE YOUTH IN BATHINDA DISTRICT OF PUNJAB".

Drug addiction has become a serious problem which has affected millions of people including the youth who are supposed to be the torchbearers of the next generation. The young generation may be considered as the back bone for any country. The harmful effect of narcotic drugs, tells heavily on the psychological and physical make -up of this generation. It impedes the all round development of our nation. The gravity of drug abuse problem can be gauged from the fact that "A particular problem is the rising the number of injecting drug users," further adding this risk "epidemic of blood borne diseases "and viruses such as Hepatitis and HIV (Aids). The situation becoming more serious due to the number of drug addicts for the past five years had been growing at an "alarming rate." These drug abusers were directly or indirectly affecting individually, family members and society with psychological social and economic repercussions.

The problem of drug abuse with its multiple aspects is a major threat to society and it's steadily trapping almost all social strata. In this situation, it is of utmost need to focus on the dimension and seriousness of this problem. It is also urgent to find out the root causes behind drug addiction in terms of socio-economic factors. To ease the situation, we should take a serious and systematic attempt to arrest the causes of drug abuse. In order 
to do so the present study would like to pay attention to individual cases of drug abuse.

\section{FINDINGS}

Following the brief summary of the findings revealed from simple tables:

1) Personal profile of the drug addicts

1.1 The age distribution for the respondents of the present study depicts that the majority of the respondents belong to age group below 30 years.

1.2 According to the gender all male population in this study.

1.3 majority of the respondent's mother tongue was Punjabi.

1.4 Majority of the respondents birth place was urban.

1.5 majority of the respondents $(62 \%)$ were sikh.

1.6 majority of the respondents were illiterate.

1.7 Majority of the respondents (62\%) were unemployed. The majority of respondents had personal income less than 3,000 Rs per month.

1.8 the majority of the respondents had no religious education.

1.9 the majority of the respondents were belongs to the nuclear family .

\section{2) Drug Profile}

1.10 Tthe absolute majority of the respondents were Heroin (42\%) addict.

1.11The majority of respondents were using drugs with friends.

1.12 The majority of respondents used drugs in unoccupied buildings and under the bridge.

1.13 The majority of respondents spent Rs. 50300 daily on drugs.

1.14 the majority of respondents that drug was first introduced to them by their friends.

1.15 the majority of respondents reported that they started using drugs because of bad company.

\section{3) Effects of Drugs}

1.16 the majority of respondents reported they had no awareness of the negative effects of drugs.

1.17 the majority of respondents reported that their physical health is be defeated due to drug addiction.
1.18 the majority of respondents reported was deteriorating their social status due to drug effects of drug usage

1.19 the majority of respondents reported that their self image deterioted after drug usage.

1.20 the majority of respondents reported that they were involved in criminal affiances because of drug addiction.

\section{4) Treatment /Rehabilitation/Relapse}

1.21 the majority of respondents wanted to treatment for drugs.

1.22 the majority of respondents reported that they did not give up drugs due to drug dependency up to

now.

1.23 the majority of respondents did not get treatment for the drug addiction, due to their financial problems.

1.24 the majority of respondents did not get any specific trinity for rehabilitation.

1.25 the majority of respondents had family support before drug addiction.

1.26 the majority of respondents had no family support in rehabilitation process.

\section{References}

1. Bansal Pir Dutt and Kalra Indivar (2011) Sociodemograpic profile and pattern of drug abuse among patients presenting to a de-addiction centre in rural area of Punjab.

2. Blum,k;(1984)Hand Book of abuseable drugs. Garden Press, New York

3. Choudhury, Sudip Kumar (2004) drug addiction among the youths in Calcutta; A sociological analysis progressive publishers, Kolkata.

4. Chopra,R, Militant and Migrant :The Politics and Social History of Punjab, London: Routledge.

5. Dutta, S,2012, Green Revolution Revisited : The Contemporary Agrarian Situation in Punjab, India, Social Change , 42 (2) ,pp.229-247.

6. Government of India:, (2007), Crimes in India , New Delhi: National Crime 
Records Bureau, Ministry of Home Affairs.

7. Government of India:,(2008) , National Family Health Survey 111, 2005-2006. New Delhi : Ministry of Health and Family Welfare.

8. Gulalia, Akash (2010)Alcoholism and substance abuse prevention in India,Mohit Publications New Delhi.

9. Kumar , Sanjay, (2004), India has Wide Spread Drug Problem.

10. Narcotic Control Bureau Bulletin, 2005.

11. Narula, Sukhwinder, Singh (2006), A Locality of Widows Maqboolpura, Amritsar : Citizens Forum Vidya Mandir.

12. Neerja and V.Goyal, (2001), Substance Abuse in Punjab, Institute for development and communication, Chandigarh.

13. Paul,Madan c.(2005)Drugs \& substance abuse problems Mittal Publications, New Delhi.

14. Priti A,Chavan BS, Kaur H Study of Reasons for not Seeking treatment for Substance abuse community Indian journal of Psychiatry, 2004,46(3) 256-260.

15. Ropar,c(2006).Social use,abuse and addiction site of the author, university of Texas, Austin. 